\title{
Design Concepts for the Development of a Semi-autonomous Robotic Platform for Environment Friendly Agriculture
}

\author{
P. Athira ${ }^{1 *}$, P. S. James ${ }^{2}$, J. J. L. Bovas ${ }^{3}$ and D. S. Khatawkar ${ }^{1}$ \\ ${ }^{1}$ Department of Farm Machinery and Power Engineering, Kerala Agricultural University, \\ Tavanur, Malappuram, Kerala, India \\ ${ }^{2}$ Agricultural Research Station, Kerala Agricultural University, Mannuthy, \\ Thrissur, Kerala, India \\ ${ }^{3}$ Department of Agricultural Engineering, Gandhigram Rural Institute University, \\ Dindigul, Tamilnadu, India \\ *Corresponding author
}

\begin{abstract}
A B S T R A C T
Escalated food demands propelled by the ever increasing population demands for increase in crop production. But problems like labour shortages, high input costs and conventional farming practices makes agriculture economically unviable and resulted in its decline, especially in vulnerable communities of the developing world. Use of heavy machinery has been in the increase to tackle the problems of labour shortages but have adverse effects on environment due to soil compaction and the adverse effect on global warming owing to high fossil fuel use. Automation technologies in agriculture are promising for increasing productivity with greater precision and better economics. Agricultural robots can make a revolutionary change as they are able to perform most agricultural tasks effectively, both in field and protected environment resulting in higher crop productivity, reduced labour shortage and time saving. Current pandemic outbreak also necessitates the significance of automation for sustaining agricultural production systems. The wide applications of agricultural robots are restricted in developing countries, mainly due to their high cost and the development of an economically feasible agricultural robot will be a boon to small scale farmers. Hence suitable design concepts were evolved for a semi-autonomous robotic platform for intercultural operations in row crops. The various design aspects for chassis, drive mechanism, wireless control system, operational unit, and the hardware and software are conceived in consideration of the techno-economic background of the developing world.
\end{abstract}

Keywords

Agricultural robots,

Design concepts,

Drive mechanism,

Wireless control

Article Info

Accepted:

17 October 2020

Available Online:

10 November 2020

\section{Introduction}

Agriculture is the primary source of livelihood in many countries all over the world, including India (Kadiyala et al., 2014).
Agriculture accounts for $18 \%$ of India's gross domestic product (Madhusudhan, 2015). India stands second in the production of fruits and vegetables. During 2018-19, the vegetable production was 187.36 million tonnes 
(Anonyms, 2019). The tremendous increase in population necessitates the increase in agricultural production to meet the food demand whereas the per capita land availability is diminishing. The conventional methods of farming, higher input costs, labour shortage, lack of water resources and problems in crop monitoring make agriculture uneconomical and inefficient, leading to decline in crop production (Yaghoubi et al., 2013; Sreekantha, 2016).

The efficiency of agricultural production systems has to be improved to meet the future requirements. The movement of labour force from rural areas to cities in search of better job opportunities has led to the increased use of agricultural machines, even though they are costly. Use of heavy machinery has been in the increase to tackle the problems of labour shortages but have adverse effects on environment due to soil compaction and resulting degradation. In addition, high fossil fuel use also has an adverse effect on global warming. The environment friendly means to tackle labour shortage is by improvised technology in agriculture, through the application of automation and robotics in agriculture (Vasconez et al., 2019). Current pandemic outbreak also signifies automation in agricultural operations for enhancing the sustainability (Yecalo et al., 2020).

Automation in agriculture has emerged as a promising methodology for increasing the crop productivity without sacrificing the product quality by saving time and labour using specified tools and technologies (Bonadies and Gadsden, 2019). Its efficiency, reliability and precision will help to enhance the productivity of agricultural machinery by reducing the human interventions. The present advancements in programming and technology have made robotics easy and less complicated. In addition to the technological easiness, the cost factor should also be considered such that it is compatible to the common farmer (Bechar and Vigneault, 2016). Hence a robotic platform, capable of providing all the advantages of agrobots at reduced cost could boost the pace of advancement of Indian agriculture. As intercultural operations remain a tedious process among all agricultural practices, automation techniques need to be implemented for helping the farming community. Therefore, an economically feasible agricultural robotic platform, capable of performing intercultural operations in row crops, must be designed. The design concepts to be adopted for developing a semiautonomous robotic platform are presented in this paper.

\section{Materials and Methods}

\section{Design considerations for the robotic platform}

A semi-autonomous robotic platform was conceptualized for performing the intercultural operations on crops cultivated in rows. It should be capable of navigating within the field and performing the intended operation according to the user command. A wireless remote controller could be used to transmit the control signals from the operator and the signals received by the robot would be processed, via a microcontroller unit, for achieving the output functions. Two types of input signals would be used, one for motion control and the other for control of the operation unit. The robot could execute the motion control in forward, reverse, and turn on both left and right side directions using drive motors and the end effector. Similarly, in the operation unit, a provision for adjusting the position of functional components (such as boom in the case of a sprayer) should be provided along with the control of the operation unit (spray pump ON/OFF). 


\section{Mechanical design of the robotic platform}

The dimensions of the chassis would be deciding based on the agronomic characteristics of the crop; row spacing and plant height. As the platform was intended to operate over the crop, ground clearance provided should be higher than the plant height. The track width of the platform was decided based on row-spacing. The material chosen for fabrication should have enough strength to carry loads with optimum material weight.

\section{Drive mechanism}

A six-wheel independent drive mechanism using six high torque geared motors was conceptualized for ensuring better stability and steady movement. The skid-steering mechanism would be used because of its simplicity and robustness. The drive mechanism comprised of drive motors, motor drivers and microcontroller unit. The selfpropulsion of the chassis was accomplished using DC motors. High torque - low speed motors are ideal for agricultural domain. The capacity of the motor to drive the robot was determined based on the torque-speed characteristics. Total tractive force was considered as the sum of forces due to rolling resistance and gradient force. Force due to acceleration and aerodynamic drag was negligible. Torque required depends upon the gross weight of the robot, velocity of travel, wheel diameter and soil properties.The equations for calculating the required torque on each motor are given below.

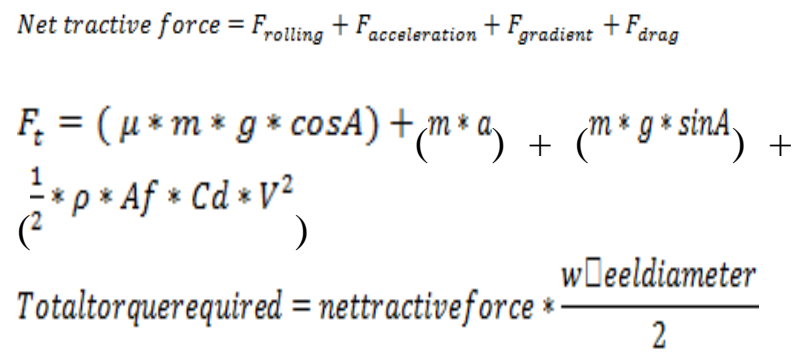

Torquerequiredoneac $\square$ motor $=\frac{\text { Totaltorque }}{\text { no. of motors }}$

Where,

$\mathrm{m}=$ gross weight of the robotic platform, $\mathrm{kg}$

${ }^{\mu}=$ coefficient of rolling resistance

$\mathrm{A}=$ angle between the ground and slope (usually $10^{\circ}$ )

$\mathrm{a}=$ acceleration of the robot, $\mathrm{ms}^{-2}$

$\rho=$ density of air, $\mathrm{kgm}^{-3}$

$A_{f}=$ frontal area of robot, $\mathrm{m}^{2}$

$C_{d}=$ Coefficient of drag

$V=$ Velocity of the robot relative to air, $\mathrm{ms}^{-1}$

The rated continuous torque of the motor should be higher than required torque. The movement of the robotic platform could be controlled by directing the rotation of drive motors using a pre-programmed microcontroller. The direction of rotation of the motor could be accomplished by changing the polarity of the power supply using motor drivers. Usually DC motor drivers are equipped to control both speed and direction.

\section{Wireless control system}

The wireless communication was established using 2.4 GHz Radio-Frequency transmitter and receiver unit, which is widely used for its advantages like lower interference, higher performance, safety, smooth data transmission, and less power consumption over other frequency ranges. The transmitter and receiver could be connected each other via a unique ID for avoiding interference from noise signals.

The user could transmit signals through a remote controlled transmitter. A receiver unit would receive the transmitted signals. In order to process these signals, the receiver had to be connected to a microcontroller unit. 
For a semi-autonomous robot, the motion and direction control were carried out by human interventions i.e., the user has to monitor the field conditions and control the robot accordingly. The monitoring and the direction control of the robot could be accomplished with the help of a real-time video transmission system. A Wi-Fi enabled camera could capture the video and enable the realtime transmission with its paired Android device. Also, the two-way communication was possible to control the pan and tilt angles of the camera module through the host Android device.

\section{Operational unit}

The operational unit was a sprayer unit comprising of two equal capacity spray tanks for carrying the spray solution. A diaphragm pump could be employed for pumping the spray solutions from the tank to nozzles. Operational unit would be mounting at the rear portion of the platform. A provision for adjusting the boom position could be achieved by utilizing a geared DC motor operated cable drive slider mechanism. The operational unit was controlled by the relays interfaced with the microcontroller via driver circuits.

\section{Power supply unit}

All the components of the robotic platform were powered by a rechargeable storage battery source. The battery capacity was approximated based on total power required for working the platform. Suitable voltage regulators could also be used for stepping down the battery voltage to operational voltage of the circuit components.

\section{Design of the robotic platform}

The principal control unit (PCU) is the brain of the robot where all the functions of the robot were controlled. The major functions of the control unit include motion control of the robot and spraying operation. The study on various microcontroller units helped for the proper selection of controller, i.e., Arduino Mega microcontroller board.

The controller should be programmed using suitable software to process the commands from the user. The controller would be programmed in Arduino IDE software using $\mathrm{C} / \mathrm{C}++$ programming language. All the supporting electronic units could be provided accordingly to develop the control unit. Here the robot would be working wirelessly via a remote controller. The control unit consisted of a wireless receiver unit, microcontroller board, voltage regulator, motor shields, relays, other electronic components, etc. These should be properly connected to accomplish the indented operations.

\section{Results and Discussion}

A conceptual design of a semiautonomous robotic platform was developed for performing intercultural operations in row crop (Fig. 4). The basic robotic platform should serve as a multipurpose platform by the attachment/detachment of suitable gadgets. Here, a spraying unit could be mounted on to the platform for the application of pesticides/spraying liquids. As the user could operate the robot from a safer distance, health hazards caused due to the direct exposure of chemical spray liquids could be avoided. The prototype was designed to operate in such a way that it could move through the crop rows and perform the spraying operation, according to the command from the operator. The operator could guide the robot as per the real-time video streaming transmitted from the robot. All the operations of the robot could be controlled by the user through a remote control unit (Fig. 1-5). 
Int.J.Curr.Microbiol.App.Sci (2020) 9(11): 2240-2246

Fig.1 Functional unit of the system

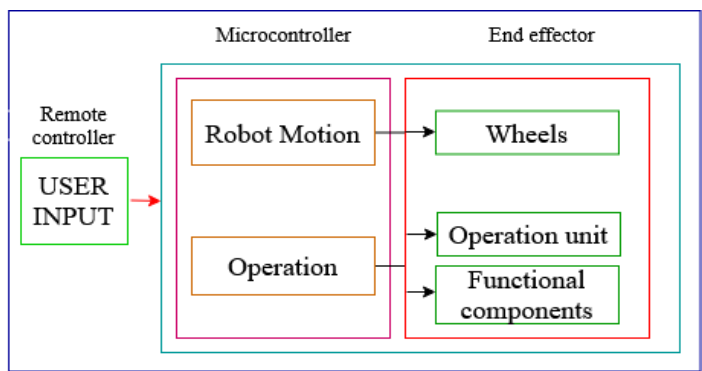

Fig.2 Forces acting upon robotic platform moving on a terrain

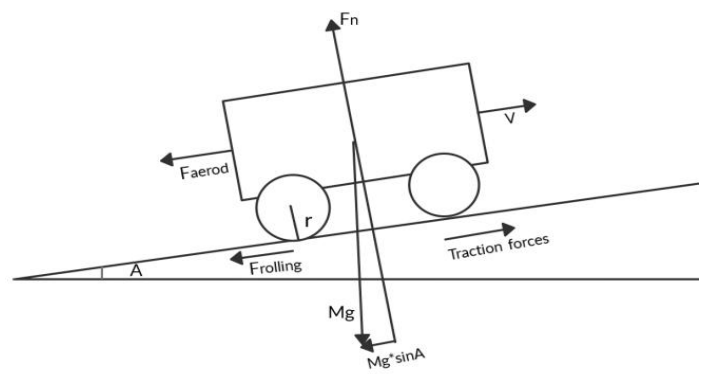

Fig.3 Block diagram of the control unit

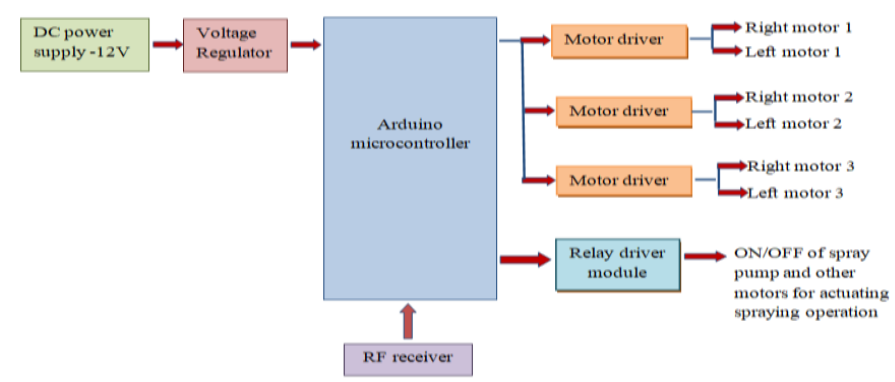

Fig.4 Flow chart of algorithm

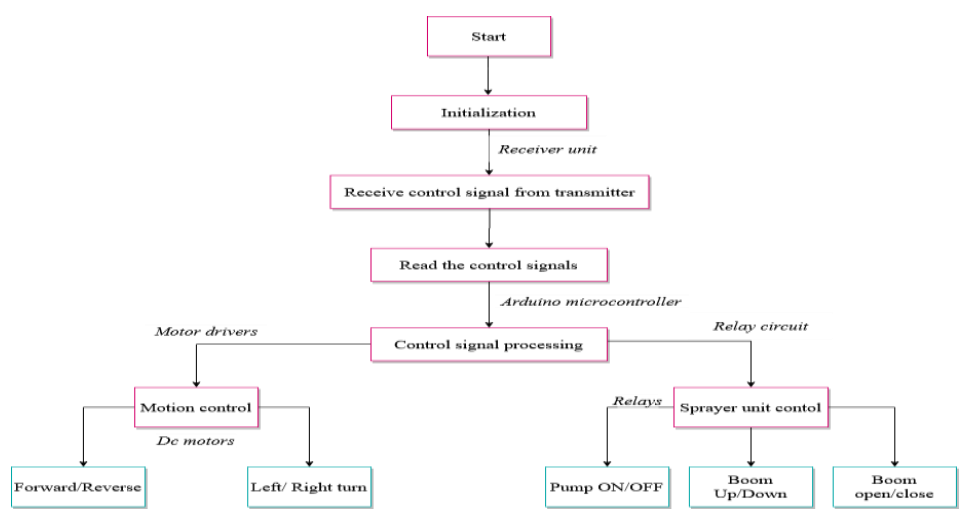


Fig.5 Conceptual design of the robotic platform

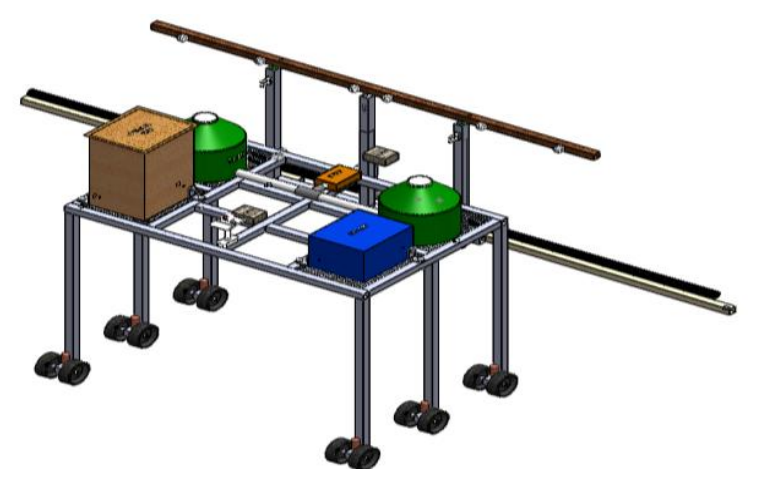

The adjustable chassis of the rover platform could ensure a variable track width and allows the user to operate the platform according to the agronomic characteristics of crops. Most of the agrobots are usually four-wheeled robots/rovers. A six-wheel-drive robot, equipped with high torque geared DC motors, was designed for carrying the loads and providing better stability. All the functional units of the robot were properly assembled over the chassis for equal load distribution and sensible utilization of the space.

In conclusion the present trend in field machinery development focus more on light agricultural robots over the conventional heavy machines in order to reduce soil compaction and energy expenditure. Even though the advancement in technologies and programming could reduce the complexity of robotics, cost is still a limiting factor among low income farmers in developing countries.

The development of the conceptual design provides the road map for an economically feasible agricultural robot in the small scale agricultural sector in India. Since agricultural robots are the future of the agriculture sector all over the world, the present study could be used as a guideline for the development of low cost robots for small farmers in resource poor countries in Asia, Africa and Latin America.

\section{References}

Department of Agriculture, Cooperation \& Farmers Welfare. 2019. Annual Report. 2018-19, $220 \mathrm{p}$. http://agricoop.nic.in/sites/default/files/ AR_2018-19_Final_for_Print.pdf [1 March 2020].

Bechar, A. and Vigneault, C. 2016. Agricultural robots for field operations: Concepts and components. Biosystems Engineering. 149: 94-111. http://doi.org/10.1016/J.BIOSYSTEMS ENG.2016.06.014.

Bonadies, S. and Gadsden, S.A. 2019. An overview of autonomous crop row navigation strategies for unmanned ground vehicles. Eng. in Agric., Environ. and Food. 12(1): 24-31. https://doi.org/10.1016/j.eaef.2018.09.0 01.

Kadiyala, S., Harris, J., Headey, D., Yosef, S. and Gillespie, S. 2014. Agriculture and nutrition in India: mapping evidence to pathways. Annals of the New York Academy of Sciences. 1331(1): 4356. http://doi:10.1111/nyas.12477.

Madhusudhan, L. 2015. Agriculture Role on Indian Economy. Business and Economics Journal. 6(4): 1.

Sreekantha, D., 2016. Automation in agriculture: a study. International Journal of Engineering Science Invention Research \& Development. 2: 
134-139.

Vasconez, J. P., Kantor, G. A. and AuatCheein, F. A. 2019. Human-robot interaction in agriculture: A survey and current challenges. Biosystems Engineering. $\quad 179$ : 35-48. http://doi:10.1016/j.biosystemseng.2018 .12 .005 .

Yaghoubi, S., Akbarzadeh, N. A., Bazargani, S. S., Bazargani, S. S., Bamizan, M. and Asl, M. I. 2013. Autonomous Robots for Agricultural Tasks and Farm
Assignment and Future Trends in Agro Robots. International Journal of Mechanical \& Mechatronics Engineering IJMME-IJENS. 13(3): 1-6. Yecalo, M. D., Joe Joe L. B., Temesgen, T., James, P. S., James, A., Michael, Y. B. and Jayaraman, S. 2020. Automation and Robotics for Crisis Management of Agriculture in Developing Countries, Glasstree Academic Publishing, ISBN: 978-1-5342-9897-2, 136p.

\section{How to cite this article:}

Athira, P., P. S. James, J. J. L. Bovas and Khatawkar, D. S. 2020. Design Concepts for the Development of a Semi-autonomous Robotic Platform for Environment Friendly Agriculture. Int.J.Curr.Microbiol.App.Sci. 9(11): 2240-2246. doi: https://doi.org/10.20546/ijcmas.2020.911.269 